\title{
What is the impact of active management on biodiversity in forests set aside for conservation or restoration? A systematic review protocol
}

Claes Bernes ${ }^{1 *}$, Bengt Gunnar Jonsson ${ }^{2}$, Kaisa Junninen ${ }^{3}$, Asko Lõhmus $^{4}$, Ellen Macdonald ${ }^{5}$, Jörg Müller ${ }^{6}$ and Jennie Sandström²

\begin{abstract}
Background: The traditional approach to limiting impacts of forestry on biodiversity is to set aside forest areas of particular conservation interest, either as formally protected reserves or on a voluntary basis. Many set-asides are left more or less untouched, but some of them have a history of disturbances such as wildfires, forest grazing, coppicing or small-scale felling. Such areas may gradually lose the qualities that were to be safeguarded unless the disturbances are re-introduced (e.g. by burning) or replaced with alternatives (e.g. gap-felling). Active management of forest set-asides may be particularly relevant in areas where the biota has been impoverished by intensive and large-scale harvesting. Here, biodiversity may not be able to recover adequately without restoration measures such as gap-felling or creation of dead wood.

In recent years, interest in active management of forest set-asides has increased, but opinions differ among conservationists on how such management should be balanced against non-intervention. The topic of the proposed systematic review has therefore met approval among stakeholders in Sweden, where it is currently an issue of high concern.

Methods: The review will examine primary field studies of how various forms of active management have affected biodiversity in boreal or temperate forests set aside for conservation or restoration. The primary focus will be on forest types represented in Sweden. In some cases, useful insights about management options may also be provided by studies of interventions in commercially managed forests. Non-intervention or alternative forms of active management will be used as comparators. Relevant outcomes include assemblage diversity (species richness, diversity indices), abundance of different functional or taxonomic groups of organisms, population viability of target species, and indicators of forest biodiversity such as forest structure and amounts of dead wood.

The relevant scientific literature may turn out to be very heterogeneous, however. Numerous combinations of management forms and biodiversity outcomes can be conceived, and it remains to be seen whether any such combination is covered by sufficiently many studies to allow a meaningful meta-analysis. Nonetheless, it should be feasible to achieve a useful narrative synthesis of the available evidence.
\end{abstract}

Keywords: Biodiversity, Early-successional habitat, Forest conservation, Forest restoration, Forest set-aside, Forest reserve, Habitat management, Prescribed burning, Thinning, Dead wood

\footnotetext{
* Correspondence: claes.bernes@eviem.se

${ }^{1}$ Mistra Council for Evidence-Based Environmental Management

Royal Swedish Academy of Sciences, SE-104 05 Stockholm, Sweden

Full list of author information is available at the end of the article
} 


\section{Background}

\section{Conservation and restoration of forest biodiversity}

Globally, forest cover has declined over many millennia, but extensive regions in northern Eurasia and North America still remain mostly forested. Here, the area covered by forest is currently stable or even expanding. However, this stability masks impacts by large-scale forestry and other industrial activities/developments that have transformed forest ecosystems from being governed mostly by natural processes to being under strong human influence [1]. The transition has had far-reaching consequences for forest structures and dynamics, and it has been accompanied by a significant loss of forest biodiversity at all levels [2]. Genetic diversity, species richness and ecosystem variability have all decreased.

The traditional way of compensating for such consequences is to identify forest areas that have (or may develop) high natural values and set them aside as reserves, with restrictions on how they can subsequently be used. Protection of this kind is still seen as an indispensable tool for nature conservation - current global targets state that at least $17 \%$ of the total land area should be protected for the benefit of biodiversity [3]. Such a target constitutes a major challenge, however, since the proportion of forests that still have high natural values falls far short of the $17 \%$ level in many regions.

Of the 'western taiga' forest in Sweden, for instance, it has been estimated that only 2 million hectares, about $10 \%$ of its original extent, fulfils the habitat criteria of the European Species and Habitat Directive [4]. Oldgrowth characteristics in particular (such as large old trees and dead trees) have been drastically reduced in forests throughout the world, and significant parts of the biodiversity that depends on such characteristics could go extinct even in countries that remain largely forested [5].

In existing reserves too, past silvicultural use has in some cases impaired forest habitats to such a degree that they are unable to support a diverse flora and fauna. For example, the extensive forest-reserve networks that have been established in Estonia and Germany are still dominated by mid-aged second-growth forests, and 10\% of the area covered by the Estonian network has also been degraded by artificial drainage [6,7].

In some areas still untouched by large-scale forestry, e.g. the montane natural forests that predominate among Sweden's protected forest areas, vegetation is shaped primarily by small scale internal dynamics, i.e. the ageing and death of fully grown trees and the establishment and growth of new seedlings. In most forest reserves in such areas, biodiversity can be preserved under a nonintervention management approach (also called passive management or free development), intended to allow internal dynamics to continue undisturbed.
In many protected forests, however, the remaining biodiversity values are legacies of past disturbance regimes that nowadays are suppressed. In these cases, one may have to weigh the consequences of doing nothing against the uncertainties of active intervention. This situation is common e.g. in the boreal pine forest, which in its natural state is shaped by recurring fires that create an abundance of dead wood and keep the stands relatively sparse and mixed with a significant broadleaved component. In northern Europe, forest fires are now very rare. Pine forests in this region have therefore become denser, with an increasing preponderance of spruce ([8] and Hedwall \& Mikusinski, in prep.).

In other forest set-asides, the existing conservation interest is partly a result of earlier forest grazing (using the forest as pasture for livestock), coppicing with standards, small-scale felling or similar human influences. Since these activities were usually discontinued several decades ago, the forest has become denser and more shaded in such areas too, to the detriment of a large number of species that are dependent on a semi-open forest landscape. In Estonia, for example, the area of wooded grasslands has plummeted from 700,000 ha in 1940 to less than 10,000 ha today. As a consequence, many species are now threatened there [9].

Reserves in areas of these kinds may need some form of active management to conserve the characteristics that were the reason for setting them aside. Such management could, for instance, involve burning, thinning, girdling of trees, resumption of forest grazing, removal of undesired species or blocking of drainage ditches.

Active management designed to achieve a favourable conservation status can be particularly relevant in regions where forests have already been degraded. In such areas, the creation of a network of forest reserves with high-quality habitats may call for a combination of landscape-scale planning and stand-scale restoration. While, in this review, 'conservation' mainly refers to management intended to preserve existing natural values, 'restoration' may be defined as management intended to recreate former values that have been lost.

In some places, it could be enough to allow exploited forest areas to gradually return to a near-natural state through non-intervention, but elsewhere active measures may be required to sustain or accelerate the natural recovery [10]. Nowadays, a multitude of restoration activities are performed to counteract losses of forest biodiversity (e.g. [11]). An ambitious goal set in the EU Biodiversity Strategy is that $15 \%$ of degraded ecosystems are to be restored by 2020 .

In Sweden, the Forest Agency has estimated that, in the long term, some 500,000 ha of forest land needs to be restored if there are to be, once again, sufficient areas of those biologically valuable forest types that are 
currently in short supply in the country. Since 1999, Sweden's Environmental Code allows for reserves to be designated with the intention of recreating lost natural values. It is thus possible to establish reserves also in forest areas that recently have been clear-cut, and which therefore can be acquired at low cost.

Solutions of this nature could be particularly useful in historically deforested regions, such as Britain. There, the best option for protecting old-forest biota may be to manage mature planted forests in a way that facilitates the development of natural forest characteristics [12].

Finally, it should be noted that both conservation and restoration efforts may have to adjust to broader changes in the environment (e.g. climate change and variations in land use intensity).

\section{Swedish perspectives on active management of forest set-asides}

Of the financial resources available for conservation of Swedish forests, the largest share by far is still devoted to setting aside additional areas of valuable forest as reserves, rather than managing reserves that already have been established. In recent years, though, interest in active management of forest reserves has increased.

Several Government bills dealing with environmental or silvicultural issues have underscored the importance of maintaining the influence of fire in Swedish forests and of 'managing care-demanding forests with high natural and cultural values so that these assets are preserved and enhanced' (e.g. [13]). Various forms of active management of forest reserves are recommended in many of the action plans for threatened species that have been developed by the Swedish Environmental Protection Agency (SEPA) and county administrative boards. Several counties have also adopted regional strategies for prescribed burning of protected forests (e.g. [14]). During the years 2006-2010, the county administrative boards spent a total of $€ 13$ million on the management of forest reserves [15].

Prescribed burning and similar activities also take place at a substantial scale in forest areas that have been voluntarily set aside by forest companies and other forest owners. Interest in such measures among Swedish forest owners grew when, in 1997, it became possible for them to obtain forest certification. One criterion for certification is that at least $5 \%$ of a forest holding is voluntarily excluded from production; another is that $5 \%$ of harvested areas on dry or mesic soils are burned.

As a consequence of this development, prescribed burning of forest is now carried out over at least 1,000 ha annually in Sweden. This is of the same order of magnitude as the total present-day extent of wildfires in the country. EU-funded LIFE projects have contributed significantly to the reintroduction of forest fires and other restoration measures in Natura 2000 areas in both Sweden and Finland.

However, opinions currently differ among conservationists on how active management of forests set aside for conservation or restoration should be balanced against non-intervention. The Swedish Society for Nature Conservation [16] recently criticised SEPA for largely continuing with a traditional non-intervention policy. Questioning whether such a policy is in line with the Swedish Environmental Quality Objectives, where measures to preserve biodiversity are given high priority, the Society 'felt that parts of SEPA instead have acted as if impressions of "virginity", "primordialism" or "naturalness" were more important as goals for the protection and management of reserves than the conservation of biodiversity'.

SEPA has now published a revised strategy for the management of forest reserves [15]. According to the agency, non-intervention should be the main management strategy in objects in which internal dynamics should prevail'. Reserves in montane forests, wet forests and a number of other specific forest types are mentioned as examples of such objects, but the agency also declares that 'non-intervention contributes to perceptions of wilderness and virginity, which makes it an important management option in other forest types as well'. However, the strategy also states that various forms of active management should be given high priority in parts of the country. These management options include burning, removal of spruce, grazing, use of leaf fodder and haymaking, and maintenance or restoration of flood regimes and drained soils.

While regarding SEPA's new management strategy as acceptable, the Swedish Society for Nature Conservation maintains that day-to-day decisions taken by the agency still reflect more traditional views on how forest reserves should be managed (Kristoffer Stighäll, pers. comm.). During our consultations with stakeholders (see Additional file 1), similar criticism has also been expressed by representatives of county administrative boards.

\section{Scientific basis}

The SEPA strategy for the management of protected forests is one of many policy statements, guidelines and recommendations on forest conservation that have been published over the past decades, in Sweden and elsewhere. One common feature of much of this literature - regardless of whether it mainly recommends nonintervention, active management or both - is a lack of references to scientific evidence.

Until quite recently, few well-designed experiments had been made to investigate how forest set-asides are affected by various kinds of management. Earlier, management policies were mainly based on historical accounts or 
palaeoecological studies of land use, natural disturbance regimes and environmental qualities in the past (to the extent that they were supported by any evidence at all).

Sutherland [17] summarised the situation regarding habitat management as follows: 'Land managers should regularly carry out randomized, replicated, controlled and monitored experiments but in practice very rarely do. [...] Instead, the norm is to alter the management (often making a number of changes simultaneously), not have a control area, subjectively decide if the changes have been successful and pass on the opinions verbally.'

Even today, the evidence on which to base conservation or restoration of forests remains sparse, but there has been some improvement over the last few years. A review of management options for protected areas has been provided by Götmark [18], and a recent scoping exercise by the Mistra Council for Evidence-Based Environmental Management (Mistra EviEM) identified a limited but significant set of studies of how various ways of managing forest set-asides affect biodiversity.

Most of the studies found during the scoping exercise had been conducted in Fennoscandia or in the United States. The treatment most commonly investigated was prescribed burning, often in combination with partial cutting. Only a minority of the studies dealt with oldgrowth forest with no history of large-scale harvesting. Several of them described the restoration of certain oldgrowth characteristics (e.g. presence of dead wood or uneven-aged structure) to stands that earlier had been under even-aged management and still to some extent were used for commercial timber production. The investigated outcomes differed from case to case. Most studies focused on one or several groups of plants, fungi or animals, but some instead examined forest structure, amounts of dead wood or other environmental qualities related to biodiversity.

The only completed systematic review related to this subject has been conducted by Kalies et al. [19], who studied how thinning and burning (including wildfires) affects vertebrates (mainly birds) in Pinus ponderosa and mixed conifer forests in the southwestern United States.

Scarcity of scientific studies of how biodiversity is affected by active management in forests set aside for conservation or restoration is clearly still an obstacle for systematic reviews within this field.

\section{Objective of the review}

The primary aim of this systematic review is to clarify how the biodiversity of forest set-asides is affected by various forms of active management.

\section{Primary question}

What is the impact of active management on biodiversity in forests set aside for conservation or restoration?

\section{Components of the primary question}

Population/subject: Forests set aside for conservation or restoration of biodiversity

Intervention: Active management (e.g. prescribed burning, thinning, grazing, creation of dead wood, introduction or removal of species)

Comparator: Non-intervention or alternative types of intervention

Outcomes: Measures or indicators of biodiversity

It may be noted that in this context, the primary comparator (non-intervention) can be regarded as a management option as relevant to study in detail as any kind of active management.

Since the review is based on Swedish initiatives and funding, it will focus on types of forest that are represented in Sweden. These types include boreal and temperate forests, i.e. vegetation zones that extend over many parts of the world. Any study of how biodiversity has been affected by active management of a forest setaside within these zones may be useful as input to the review. This also means that the results of the review should be relevant not only for Sweden but for other regions as well.

The scientific literature on the topic of the review may turn out to be very heterogeneous. Numerous combinations of management forms and biodiversity outcomes can be conceived, and it remains to be seen whether any such combination is covered by sufficiently many studies to allow a meaningful meta-analysis. Nonetheless, it should be feasible to produce a useful narrative synthesis of the currently available evidence on how different forms of management affect different aspects of biodiversity. Such a synthesis would also be able to reveal the most important knowledge gaps and specify the most urgent research needs within this field.

As an alternative, it would also be possible to produce a systematic map of the subject area [20]. Such a map would give an overview of the evidence base, and it might identify subtopics that could then be addressed by full systematic reviewing.

\section{Methods}

\section{Search terms}

The review team conducted a scoping exercise to assess alternative search terms, testing them against a set of about 20 articles known to be relevant. A preliminary search string was later modified and amended based on suggestions received during the public review. This resulted in the following final selection of search terms: 
Subject: forest", woodland", "wood" pasture ${ }^{*}$, "wood" meadow"

Forest type: boreal, boreonemoral, hemiboreal, nemoral, temperate, conifer*, deciduous, broadlea*, "mixed forest", spruce, "Scots pine", birch, aspen, beech, "Quercus robur", Swed*

Intervention: conserv", restor*, rehabilitat", "active management", (prescribed OR control* OR experiment*) AND (burn* OR fire*), thinn*, (partial OR selecti* OR gap OR retention) AND (felling OR cutting OR harvest*), "green-tree retention", "introduc*, remov", graz", girdl", ditch $^{*}$, flood*, fenc*, exclos*, pollard*, coppic*

Outcomes: *diversity, species AND (richness OR focal OR target OR keystone OR umbrella OR red-list* OR threatened OR endangered OR rare), "species density", "number of species", indicator*, abundance, "dead wood", "woody debris", "woody material", "forest structure", habitat*

The terms within each of the categories 'subject', 'forest type', 'intervention' and 'outcomes' will be combined using the Boolean operator 'OR'. The four categories will then be combined using the Boolean operator 'AND'. An asterisk $(*)$ is a 'wildcard' that represents any group of characters, including no character.

The search terms within the 'forest type' category have been chosen to optimise the likelihood of finding relevant studies in Sweden or in forests elsewhere that are dominated by tree species commonly occurring in Sweden. However, the terms should also be capable of identifying a satisfactory share of relevant studies carried out in other boreal and temperate forest types throughout the world.

The selection of search terms above translates to the following search string:

English:

forest" OR woodland* OR "wood* pasture" OR "wood" meadow"

AND (boreal OR boreonemoral OR hemiboreal OR nemoral OR temperate OR conifer* OR deciduous OR broadlea* OR "mixed forest" OR spruce OR "Scots pine" OR birch OR aspen OR beech OR "Quercus robur" OR Swed")

AND (conserv* OR restor* OR rehabilitat* OR "active management" OR ((prescribed OR control* OR experiment*) AND (burn* OR fire*)) OR thinn* OR ((partial OR selecti* OR gap OR retention) AND (felling OR cutting OR harvest*)) OR "green-tree retention" OR *introduc* OR remov* OR graz* OR girdl* OR ditch* OR flood* OR fenc* OR exclos* OR pollard* OR coppic*)

AND ("diversity OR (species AND (richness OR focal OR target OR keystone OR umbrella OR red-list* OR threatened OR endangered OR rare)) OR "species density" OR "number of species" OR indicator* OR abundance OR "dead wood" OR "woody debris" OR "woody material" OR "forest structure" OR habitat*)

Searches will also be made using the following French and German counterparts to the English search string (although they in some cases will have to be simplified):

French:

forêt* OR forestièr* OR "pâturag* bois*" OR "bois prés" OR "prairie boisée"

AND (boréale OR boréonémorale OR hémiboréale OR némorale OR tempéré* OR conifère OR résineus* OR feuillu* OR "forêts mixtes" OR épinette OR "pin sylvestre" OR bouleau OR peuplier OR hêtre OR "Quercus robur" OR Suèd*)

AND (conserv* OR restaur* OR réhabilit* OR ((dirigé* OR expériment**) AND (brûlag* OR incend* OR feu)) OR éclairci* OR CPRS OR ((partiell OR jardinag* OR retention OR troué*) AND (coupe OR

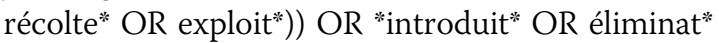
OR enlève* OR pâtur* OR annel* OR drain* OR canalis* OR inond* OR clôtur* OR exclos* OR têtard OR taillis)

AND ("diversité OR ((espèce OR taxon) AND (richesse OR vises OR cibles OR clé OR disparition OR menacé* OR rare)) OR "densité des espèce" OR "nombre des espèce" OR indicatrice* OR abondance OR "bois mort" OR "debris ligneux" OR "matériel ligneux" OR "structure de la forêt" OR habitat*)

\section{German:}

(Wald OR Wälder)

AND (boreal* OR boreonemoral* OR hemiboreal" OR nemoral* OR temperat* OR gemäßigt* OR Schwed*) OR Nadelwald OR Laubwald OR Mischwald OR Fichte* OR Waldkiefer OR Birke* OR Aspe* OR Buche* OR "Quercus robur")

AND (Naturschutz* OR Renaturierung* OR ((kontrolliert* OR Experiment*) AND Feuer) OR Durchforstung* OR Femelschlag OR Femelhieb OR Femelnutzung OR Einzelstammnutzung OR Einzelbaumnutzung OR Einzelbaumernte OR 
Lochhieb OR Einführung* OR Entnahme* OR Beweidung OR Ringeln* OR Entwässerung* OR Zaun* OR "zäunung OR Ausschluss")

AND (Diversität OR Biodiversität OR Artenvielfalt OR (Art* AND (gefährdet OR bedrohte OR seltene OR "Rote* Liste")) OR Artenzahl OR Zielart* OR Schlüsselart* OR Schirmart* OR Artendichte OR Indikatorart" OR Abundanz OR Totholz OR Waldstruktur* OR Habitat)

No time, language or document type restrictions will be applied.

At some of the websites mentioned below, searches will also be made for relevant literature in Finnish, Russian and Swedish. The search terms will have to be customised to each of these websites, since few of them accept long and complex search strings. Final search strings used for each search will be recorded in an Appendix, together with search dates.

\section{Publication databases}

The search aims to include the following online databases:

1) Academic Search Premier

2) Agricola

3) Biological Abstracts

4) GeoBase + GeoRef

5) JSTOR

6) Libris

7) Nauchnaya elektronnaya biblioteka

8) Scopus

9) SwePub

10) Web of Science

11) Wiley Online Library

\section{Search engines}

Internet searches will be performed using the following search engines:

Google (www.google.com)

Google Scholar (scholar.google.com)

In each case, the first 200 hits (based on relevance) will be examined for appropriate data.

\section{Specialist websites}

Websites of the specialist organisations listed below will be searched for links or references to relevant publications and data, including grey literature.

Ancient Tree Forum (www.ancient-tree-forum.org.uk)

Bureau of Land Management, US Dept. of the

Interior (www.blm.gov)
Environment Canada (www.ec.gc.ca)

European Commission Joint Research Centre

(ec.europa.eu/dgs/jrc)

European Environment Agency (www.eea.europa.eu)

Food and Agriculture Organization of the United Nations

(www.fao.org)

Finland's environmental administration (www.ymparisto.fi) International Union for Conservation of Nature (www. iucn.org)

Metsähallitus (www.metsa.fi)

Natural Resources Canada (www.nrcan.gc.ca)

Nordic Council of Ministers (www.norden.org)

Norwegian Environment Agency

(www.miljødirektoratet.no)

Norwegian Forest and Landscape Institute

(www.skogoglandskap.no)

Norwegian Institute for Nature Research (www.nina.no)

Parks Canada (www.pc.gc.ca)

Society for Ecological Restoration (www.ser.org)

Swedish County Administrative Boards

(www.lansstyrelsen.se)

Swedish Environmental Protection Agency

(www.naturvardsverket.se)

Swedish Forest Agency (www.skogsstyrelsen.se)

Swedish University of Agricultural Sciences (www.slu.se)

UK Environment Agency (www.environment-agency. gov.uk)

United Nations Environment Programme (www.unep.org)

United States Environmental Protection Agency

(www.epa.gov)

US Forest Service (www.fs.fed.us)

\section{Other literature searches}

As a check of the comprehensiveness of our searches, relevant articles and reports will also be searched for in bibliographies of literature reviews. Moreover, each member of the review team will use national and international contacts to get information on current research related to the topic of the review, and also to find nonpeer-reviewed literature, including reports published in e.g. Swedish, Finnish, Estonian or Russian. In addition, unpublished data (e.g. records of prescribed fires and other interventions) may be available from forest owners, consultants or local authorities involved in the management of forest set-asides. Stakeholders will be asked to suggest suitable contacts.

\section{Study inclusion/exclusion criteria}

Articles found by searches in databases will be evaluated for inclusion at three successive levels. First they will be assessed by title by a single reviewer. In cases of uncertainty, the reviewer will tend towards inclusion. As a check of consistency, a subset of 100 titles will be assessed by all members of the review team. If the main 
reviewers' assessments tend to differ from those of the other team members, the team will discuss and agree on how the inclusion criteria should be interpreted.

Next, each article found to be potentially relevant on the basis of title will be judged for inclusion on the basis of abstract. The reviewer will tend towards inclusion in cases of uncertainty. A subset consisting of at least 100 of the articles will be assessed by at least two reviewers. A kappa statistic [21] relating to the assessments will be calculated. If this statistic indicates that the reviewers are inconsistent in their assessment $(\kappa<0.6)$, discrepancies will be discussed and the inclusion criteria will be clarified or modified.

Finally, each article found to be potentially relevant on the basis of abstract will be judged for inclusion by a reviewer studying the full text. Again, reviewers will tend towards inclusion in cases of uncertainty. Final decisions on whether to include doubtful cases will be taken by the review team as a whole.

Studies or datasets found by other means than database searches will be entered at the last stage of this screening process.

A list of studies rejected on the basis of full-text assessment will be provided in an appendix together with the reasons for exclusion.

Each study must pass each of the following criteria in order to be included.

- Relevant subjects: Forests in the boreal or temperate vegetation zones. Any ecosystem with a tree layer will be regarded as forest, which means that studies of e.g. wooded meadows and urban woodlands may be included.

Studies of forests subject to large-scale commercial forestry may also be included, although this review deals with the management of forests set aside from forestry of that kind. The reason is that certain practices commonly applied in commercial forestry (e.g. thinning) may be useful as management options for set-asides too.

- Relevant types of intervention: Active management which is used or can be used to conserve or restore forest biodiversity. Relevant management types include but are not restricted to prescribed burning, thinning, livestock grazing, blocking of drainage ditches, introduction or removal of species, and creation of dead wood e.g. through girdling of trees. Although stakeholders suggested that studies of wildfires should be included, the review team decided not to do so. Wildfire is in most cases not a management option, although it may be possible to choose whether to suppress a fire or not, and while there is an extensive literature on the effects of unplanned and uncontrolled fires (e.g. [22,23]), their consequences for biodiversity cannot be assumed to be identical to those of prescribed burning. Studies have been made of prescribed burning too, and we judge that they will be sufficient for the needs of this review.

We will also exclude studies of restrictions of public access and creation of artificial habitats such as provisioning of artificial nest sites for vertebrates (the latter management option has already been extensively reviewed, e.g. by Newton [24]).

- Relevant type of comparator: Non-intervention or alternative types of intervention.

- Relevant types of outcome: Measures or indicators of biodiversity in the terrestrial environment. Relevant measures of biodiversity include e.g. species richness, diversity indices and abundance of different taxonomic or functional groups of organisms, and also the population viability of target species. Forest structure and amounts of dead wood are two examples of relevant indirect biodiversity indicators.

- Relevant type of study: Primary field studies. This criterion excludes e.g. modeling studies and review papers.

- Language: Full text written in English, French, German, Danish, Norwegian, Swedish, Finnish, Estonian or Russian.

\section{Potential effect modifiers and reasons for heterogeneity}

To the extent that data are available, the following potential effect modifiers will be considered and recorded:

\author{
Geographical coordinates \\ Altitude \\ Climate (and climate change) \\ Mean age of forest stand \\ Dominant tree species \\ Stand productivity \\ Type and areal extent of forest set-aside \\ Type, areal extent, duration and intensity of \\ management activities \\ Time elapsed from management activities to final data \\ sampling \\ Landscape aspects (such as degree of isolation) \\ History of land use and protection
}

When assessing the outcomes of conservation efforts in set-aside forest areas, the land-use legacy must never be overlooked. It will also be necessary to consider conditions in the surroundings of such areas. Many reserves lie like scattered islands in a 'sea' of efficiently managed but species-poor timber production forest. This fragmentation of less exploited, species-rich natural forest can make it difficult to maintain biodiversity within the 'islands' set aside from forestry. 
A final list of modifiers and causes of heterogeneity to be recorded will be established as the review proceeds.

\section{Study quality assessment}

Studies that have passed the relevance criteria described above will be subject to critical appraisal. Based on assessments of their validity, they will be categorised as having high, medium or low susceptibility to bias (e.g. due to presence or absence of replication or data on variance and potential effect modifiers). Studies with high susceptibility to bias will be excluded from the review.

The exact criteria to be applied when assessing study quality will be developed as the review proceeds, but factors such as methodological description, duration between intervention and data sampling, accounting for potential effect modifiers, replication and statistical treatment are likely to feature prominently among them.

Comparison of how different kinds of management affect biodiversity can in principle be made both temporally and spatially. Studies with a 'BA' (Before/After) design compare data collected at the same site prior to and following an intervention. Other studies may be based on comparison of different parts of a forest, some that have been subject to a certain kind of active management and some that have not. These may be termed as 'CI' (Comparator/Intervention) studies, or 'BACI' (Before/After/Comparator/Intervention) if they present data collected both before and after the intervention.

In practice, studies with a CI or BACI design are likely to be more useful than BA studies in the context of this review. This is because of the long time-scale of forest ecosystem changes, which means that a forest set-aside that has been subject to some kind of active management may also be affected by other influences (e.g. climate change, nitrogen deposition, or ecological succession following earlier land-use changes) before management effects have had time to develop fully. Such influences can be controlled for in CI and BACI studies, but not in BA studies.

Detailed reasoning concerning critical appraisal will be recorded in a transparent manner. In general, the quality of a study will be assessed by one reviewer, but final decisions on how to judge doubtful cases will be taken by the review team as a whole.

A list of studies rejected on the basis of quality assessment will be provided in an appendix together with the reasons for exclusion.

\section{Data extraction strategy}

Outcome means and measures of variation (standard deviation, standard error, confidence intervals) will be extracted from tables and graphs, using image analysis software when necessary. As a rule, we will extract data on major functional or taxonomic groups, but not on individual species or genera. Where time-series of data are available, we will only extract the most recent results (plus pre-intervention data from BA and BACI studies). Data on interventions and other potential effect modifiers will also be extracted from the included articles, but climatic data will be downloaded from the WorldClim database [25].

It may in some cases be useful to ask authors of relevant articles to supply data in digital format. This will primarily be done where useful data have been published in graphs from which they are difficult to extract accurately enough, or when it is known or assumed that considerable amounts of relevant but unpublished data may be available in addition to the published results. If raw data are provided, summary statistics will be calculated by us.

\section{Data synthesis and presentation}

A narrative synthesis of data from all studies included in the review will describe the quality of the results along with the study findings. Tables will be produced to summarise these results. Where studies report similar outcomes, meta-analysis may be possible. In these cases effect sizes will be standardised and weighted appropriately. Details of the quantitative analysis will only be known when full texts have been assessed for their contents and quality.

If meta-analysis of effect sizes is possible, it will take the form of random-effects models, and meta-regression will be performed where effect modifiers cause significant heterogeneity between studies. Subgroup analysis of categories of studies will also be performed where sufficient studies report common sources of heterogeneity. Publication-bias and sensitivity analysis will be carried out where possible. Overall management effects will be presented visually in plots of mean effect sizes and variance.

As an alternative to a full systematic review (or in addition to such a review), we may compile a systematic map of the evidence base. Such a map would be produced in an easily searchable format and provide basic data on the studies that we have found to be relevant, including study locations, forest types, types of intervention and types of reported outcomes.

\section{Additional file}

Additional file 1: Identification of topic and stakeholders.

Competing interests

The authors declare that they have no competing interests. 


\section{Authors' contributions}

All authors participated in the drafting, revision and approval of the manuscript. All authors read and approved the final manuscript.

\section{Acknowledgements}

We are grateful for valuable comments and advice received from a considerable number of stakeholders, both at meetings in the initial phase of this project and during the public review of the protocol. The review will be financed by the Mistra Council for Evidence-Based Environmental Management (EviEM).

\section{Author details}

${ }^{1}$ Mistra Council for Evidence-Based Environmental Management Royal Swedish Academy of Sciences, SE-104 05 Stockholm, Sweden. ${ }^{2}$ Department of Natural Sciences, Mid-Sweden University, SE-851 70 Sundsvall, Sweden. ${ }^{3}$ Metsähallitus Parks \& Wildlife Finland, c/o UEF, P.O. Box 111Fl-80101 Joensuu, Finland. ${ }^{4}$ Institution of Ecology and Earth Sciences, Tartu University, Vanemuise 46, 51014 Tartu, Estonia. ${ }^{5}$ Department of Renewable Resources, University of Alberta, 751 General Services Building, Edmonton, AB T6G 2H1, Canada. ${ }^{6}$ Department of Conservation and Research, Bavarian Forest National Park, Freyunger Str. 2, 94481 Grafenau, Germany.

Received: 16 June 2014 Accepted: 22 September 2014 Published: 5 November 2014

\section{References}

1. Schelhaas MJ, Nabuurs GJ, Schuck A: Natural disturbances in the European forests in the 19th and 20th centuries. Glob Chang Biol 2003, 9:1620-1633.

2. Secretariat of the Convention on Biological Diversity: Global Biodiversity Outlook 3. Montréal: Secretariat of the Convention on Biological Diversity; 2010.

3. Convention on Biological Diversity: Strategic Plan for Biodiversity 2011-2020, COP Decision X/2. Aichi; 2010.

4. Eide W: Arter och naturtyper i habitatdirektivet - bevarandestatus i Sverige 2013. Uppsala: ArtDatabanken, SLU; 2014.

5. Hanski I: Extinction debt and species credit in boreal forests: Modelling the consequences of different approaches to biodiversity conservation. Ann Zool Fennici 2000, 37:271-280.

6. Lõhmus A, Kohv K, Palo A, Viilma K: Loss of old-growth, and the minimum need for strictly protected forests in Estonia. Ecol Bull 2004, 51:401-411.

7. Meyer P, Schmidt M, Spellmann H, Bedarff U, Bauhus J, Reif A, Späth V: Aufbau eines Systems nutzungsfreier Wälder in Deutschland. Natur und Landschaft. Zeitschrift für Naturschutz und Landschaftspflege 2011, 86:243-249.

8. Linder P: Structural changes in two virgin boreal forest stands in central Sweden over 72 years. Scand J For Res 1998, 13:451-461.

9. Sammul M, Kattai K, Lanno K, Meltsov V, Otsus M, Nõuakas L, Kukk D, Mesipuu M, Kana S, Kukk T: Wooded meadows of Estonia: conservation efforts for a traditional habitat. Agric Food Sci 2008, 17:413-429.

10. Bernes C: Biodiversity in Sweden. Stockholm: Swedish Environmental Protection Agency, Monitor 22; 2011.

11. Halme P, Allen KA, Auninšs A, Bradshaw RHW, Brūmelis G, Čada V, Clear JL, Erikssom AM, Hannon G, Hyvärinen E, Ikauniece S, Iršėnaitè R, Jonsson BG, Junninen K, Kareksela S, Komonen A, Kotiaho JS, Kouki J, Kuuluvainen T, Mazziotta A, Mönkkönen M, Nyholm K, Oldén A, Shorohova E, Strange N, Toivanen T, Vanha-Majamaa I, Wallenius T, Ylisirniö AL, Zin E: Challenges of ecological restoration: Lessons from forests in northern Europe. Biol Conserv 2013, 167:248-256.

12. Humphrey JW: Benefits to biodiversity from developing old-growth conditions in British upland spruce plantations: a review and recommendations. Forestry 2005, 78:33-53.

13. Swedish Ministry of the Environment: Svenska miljömål - för ett effektivare miljöarbete, Government Bill 2009/10:155. Stockholm; 2010.

14. Östergötland County Administrative Board: Strategi för naturvårdsbränning i sydöstra Sveriges skyddade skogsområden år 2012-2022. Bakgrund, analys och genomförande. 2012. Meddelande 2012:13 http://www.lansstyrelsen.se/ ostergotland/SiteCollectionDocuments/Sv/djur-och-natur/skyddadnatur/ Naturvårdsbränning/rapp2012_13Ekologiskt_brandstrategi_ orginal_webb.pdf.

15. Swedish Environmental Protection Agency: Förvaltning av skogar och andra trädbärande marker i skyddade områden, Rapport 6561. Stockholm; 2013.
16. Swedish Society for Nature Conservation: Möjliggör skötsel av skyddad skog för att bevara hotade arter, Letter to SEPA. 2012. [http://www2. naturskyddsforeningen.se/upload/Foreningsdokument/Ovrigt/Skrivelse_sk\% C3\%B6tsel_av\%20skogsreservat.pdf]

17. Sutherland WJ: Managing Habitats and Species. In Conservation Science and Action. Edited by Sutherland WJ. Oxford: Blackwell; 1998:202-219.

18. Götmark F: Habitat management alternatives for conservation forests in the temperate zone: Review, synthesis, and implications. For Ecol Managem 2013, 306:292-307.

19. Kalies E, Covington W, Chambers C, Rosenstock S: How do Thinning and Burning Treatments in Southwestern Conifer Forests in the United States Affect Wildlife Density and Population Performance? Collaboration for Environmental Evidence: CEE review 09-005 (SR66). 2010. http://www. environmentalevidence.org/Documents/Completed_Reviews/SR66.pdf.

20. Collaboration for Environmental Evidence: Guidelines for Systematic Review and Evidence Synthesis in Environmental Management, Version 4.2, p. 37 Environmental Evidence. 2013. www.environmentalevidence.org/ Documents/Guidelines/Guidelines4.2.pdf.

21. Landis JR, Koch GG: The measurement of observer agreement for categorical data. Biometrics 1977, 33(1):159-174.

22. Kuuluvainen T, Aakala T: Natural forest dynamics in boreal Fennoscandia: a review and classification. Silva Fennica 2011, 45:823-841.

23. Gromtsev A: Natural disturbance dynamics in the boreal forests of European Russia: A review. Silva Fennica 2002, 36:41-55.

24. Newton I: Population Limitation in Birds. London: Academic Press; 1998.

25. Hijmans RJ, Cameron SE, Parra JL, Jones PG, Jarvis A: Very high resolution interpolated climate surfaces for global land areas. Int J Climatol 2005, 25:1965-1978.

doi:10.1186/2047-2382-3-22

Cite this article as: Bernes et al: What is the impact of active management on biodiversity in forests set aside for conservation or restoration? A systematic review protocol. Environmental Evidence 2014 3:22.

\section{Submit your next manuscript to BioMed Central and take full advantage of:}

- Convenient online submission

- Thorough peer review

- No space constraints or color figure charges

- Immediate publication on acceptance

- Inclusion in PubMed, CAS, Scopus and Google Scholar

- Research which is freely available for redistribution 